Magnus Ronn | LM Tucker | Ron Dulaney Jr. Sinclair, Mousazadeh, Safarzadeh | James Shraiky Marci Uihlein | Tang, Anderson, Aksamija, Hodge

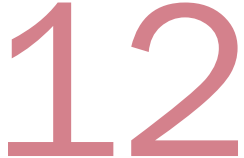

volume 9 | issue 1

\section{Agility, Adaptability + Appropriateness: Conceiving, Crafting \& Constructing an Architecture of the 21st Century}

\author{
Dr. Brian R. Sinclair, FRAIC | Somayeh Mousazadeh | \\ Ghazaleh Safarzadeh \\ Faculty of Environmental Design - University of Calgary + \\ sinclairstudio inc., Calgary, Alberta, Canada
}

\section{ABSTRACT}

Architectural design in our current times has tended to generate buildings which, despite their aesthetic qualities, frequently prove static, rigid and intractable. The intense and significant production of architecture around the planet has created a situation whereby modification of the existing building stock is costly, difficult and at times implausible. Beginning in the mid-twentieth century architects began to more seriously question narrow design approaches and in response explored more open, mutable and responsive ways of building. Architects such as Kisho Kurokawa and Cedric Price, in an effort to envision more resilient \& robust solutions, explored methods of design and construction which afforded greater user control, modification and customization of environments. As opposed to buildings in which users needed to adapt to environmental constraints, these progressive designers imagined spaces that adjusted to user needs. A significant challenge to these visionaries was a lag between thinking and technology - quite simply construction proved unable to fully address concept. Today the world has changed in dramatic ways, with advancements in technology, expectations of society, and a quest for greater sustainability all driving a push for more agile, adaptable and appropriate Architecture. The present paper critically contemplates the condition of contemporary building design, examines emerging trends, and postulates an innovative model \& philosophy for realizing a more responsive, responsible and fitting Architecture for the 21st Century. While considering historical initiatives, theories and practices, the paper also examines contemporary applications and future possibilities, arguing that many forces hold promise to align in ways before unimaginable. Advancing from the established foundation of Open Building $(\mathrm{OB})$ research and practice, and building upon a holistic and inter-connected strategy (Sinclair 2009) for environmental design, the new model places emphasis and effort on heightened agility, adaptability and appropriateness - all urgently needed in our current, uncertain and tumultuous times.

Keywords: agility, adaptability, appropriateness, flexibility, integrative, framework, responsive, resonant, resilient

\section{INTRODUCTION}

We are now living in the age of a paradigm already evident in politics, science and technology. This cooperative spirit leads to an architecture of participation.

Kisho Kurokawa

Architectural design in our current times has tended to generate buildings which, despite their artistic qualities, frequently prove static, rigid and intractable. The intense and significant production of architecture around the planet has created a situation whereby modification of the existing building stock is costly, difficult and at times implausible. Beginning in the mid-twentieth century architects began to explore more open, mutable and responsive ways of building. Visionary architects such as the late Kisho Kurokawa (e.g., Nakagin Capsule Tower) and the late Cedric Price (e.g, The Fun Palace + The Generator), in an effort to envision more resilient \& robust solutions, explored methods of design and construction that provided greater user control, more modification, and heightened customization of environments. As opposed to buildings in which users needed to adapt to environmental constraints, these progressive designers imagined spaces that interactively adjusted to user needs.

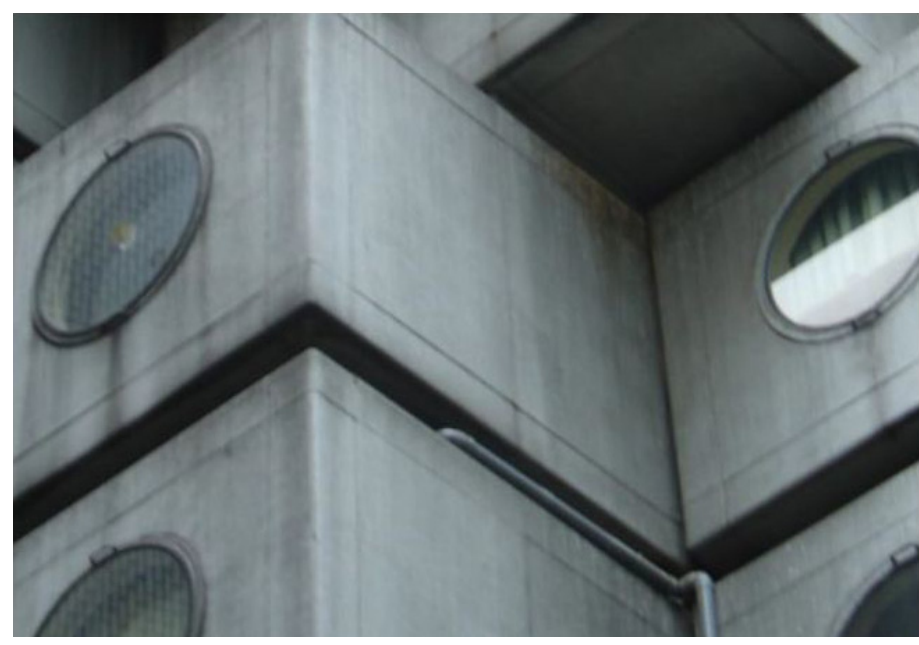

Images 1: Nakagin Capsule Tower Tokyo (1972) 


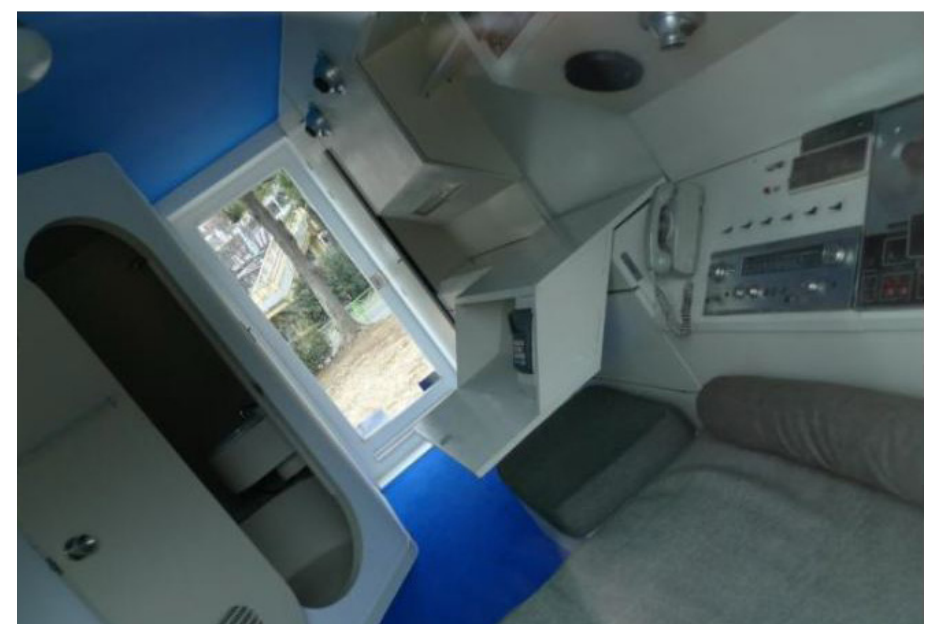

Images 2: Typical Capsule Interior Layout

A significant challenge to these design innovators was a serious lag between thinking and technology - quite simply construction proved unable to fully address concept. Today the world has changed in dramatic ways, with advancements in technology, expectations of society, and a quest for greater sustainability all driving a push for more agile, adaptable and appropriate Architecture. Into this milieu architecture and environmental design aim to provide spaces and places

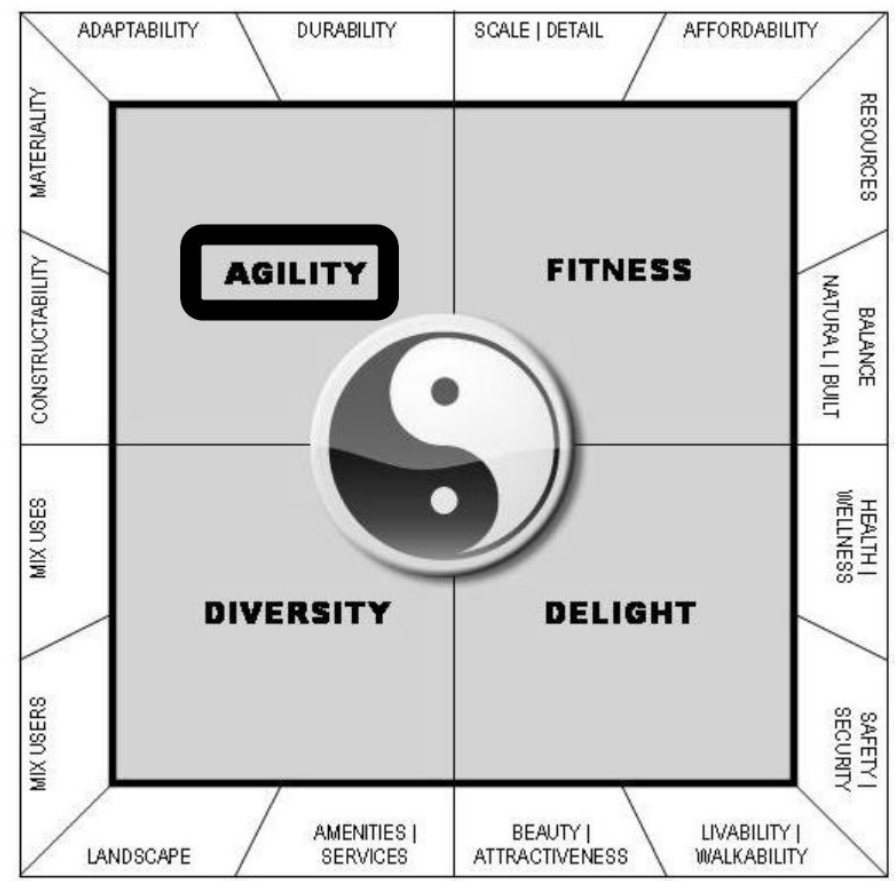

Image 3. Sinclair's Holistic Integrated Framework for Design + Planning which accommodate the needs of increasingly diverse and pluralistic communities. One of the authors (Sinclair, see for example 2009 \& 2010) has previously delineated a Holistic Integrated Framework for Design + Planning. This innovative approach, being deployed \& tested across multiple scales, considers the symbiotic interplay of Fitness, Agility, Diversity and Delight. The present paper aims to expand and explore ways of considering Agility, with a particular focus on re-conceptualising the manner in which Architecture might heighten its resonance with user needs, demands, desires and expectations. The approach, while acknowledging the rich \& remarkable developments in the field of 'open building' over many decades, proposes a novel lens through which to view and tackle agility, adaptability and appropriateness of design in our current, complex and ever-so complicated era.

The word 'flexibility' is an important term in the Open Building (OB) glossary. It describes the structures, which can be adapted in some way or other to the dynamic process of habitation (Eldonk \& Fassbinder, 1990). The current paper expands on the notion of 'flexibility' from different perspectives and through the introduction of a framework aims to shift the user's role in architectural design and practice. A sense of control over space psychologically enables the users whereas being unable to change one's surroundings can result in anxiety, distress and discomfort. The proposed strategic OB framework, as a provocative mechanism, examines agile architecture through the notions of 'spatial flexibility', 'functional flexibility' and 'aesthetic flexibility'. While this OB framework elaborates on how each three categories of 'spatial flexibility', 'functional flexibility' and 'aesthetic flexibility' contributes to the concept of agility, it further promotes an overarching mindset whereby all three cooperate as a new and more sustainable system in the design of buildings that endure. 'Resilient' design as a hybrid of 'spatial', 'functional' and 'aesthetic' flexibility responds to the users' needs and desires to reimagine + reconfigure the space, as they wish, in real time. Practicing 'open building' requires an increasing technicality that can be well addressed by today's design \& building professionals and related industries. This research endeavors to reconsider the concept of 'open building' through a more 'designerly' perspective and postulates a perhaps novel model \& philosophy for realizing a more responsive, responsible and fitting Architecture for the 21st Century.

\section{SPATIAL FLEXIBILITY}

Spatial flexibility, as an architectural theme, was among the first drivers of the 'open building' concept. It refers to the capacity of change in the spatial structure of a building. Its historical roots can be traced back to the traditional Japanese single family dwelling - an open cubic structure that was subdivided into smaller spaces by means of sliding walls in a ratio of "tatami" mats. Early multi-family dwellings with spatial flexibility appeared in Dutch housing projects. The idea behind this theme was initially introduced by the Stichting Architecten Research (SAR) and through influential architects like N. J. Habraken in the 1960s. Habraken distinguishes between 'support' and 'infill' -- where support refers to what 


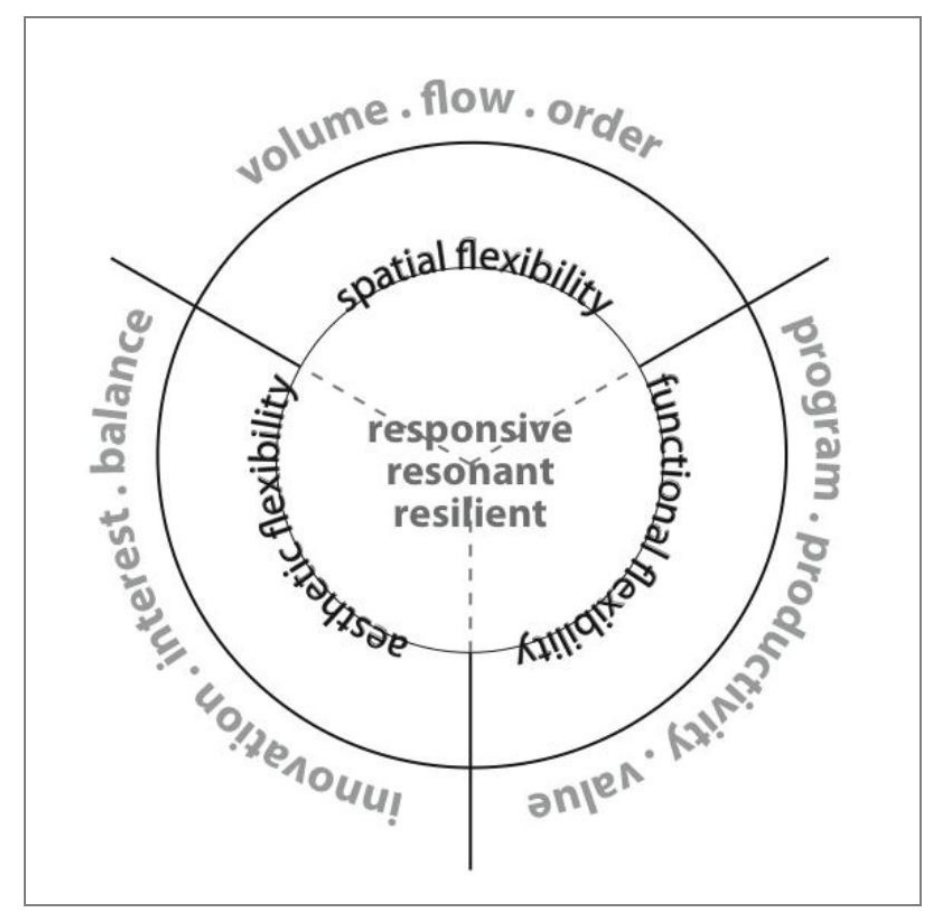

Image 4. Integrative Agility Framework

the individual user cannot change, while the infill is what the individual user can freely decide and act upon (Eldonk \& Fassbinder, 1990). In this analogy, the structure and exterior shell is fixed and designed to accommodate the flexible and changeable infill systems based on users' needs and desires. Plans tended toward large rectilinear or square layouts that are subdivided to smaller spaces by moveable interior partitions. Similar to Japanese traditional houses, flexible infill is achievable by means of sliding interior panels and foldable partitions. A related methodology deploys lightweight interior walls that were not coupled or, as Stephen Kendall (1999) notes, "entangled" with structure. Therefore, each household was able to layout the interior prior to occupation based on its own spatial needs with no disturbance in the main structural layout. In the beginning of the 1980s, the Japanese took this concept further by differentiating ownership of 'infill' from 'support'. In the 'two step housing supply system or century housing system' (CHS), the 'support' is built in the first step by the public entity with high quality and durable materials; in the second step, it is delivered to small regional construction companies to be rented to occupants. Local companies are then responsible for preparing the planning 'sheets' in which the occupants determined their desired layout, which was then constructed using lightweight materials that, while manageable, may not necessarily prove durable. This methodology rationalized a sequential construction and addressed the practice in addition to the design (Kendall, 1999). The present paper views spatial flexibility as basic to agile + progressive Architecture.

\section{Guideline}

In the design of buildings, spatial flexibility realizes the users needs and desires to make changes in the composition \& arrangement of the space. It provides the building with greater flexibility and open systems, which ultimately afford users with more control over the configuration and utilization of space(s).

\section{Elaboration}

In North America, the typical approach to design and construction of spaces tends to be very fixed and static. For each activity, a distinct space is crafted that may not be efficient especially across the fourth dimension. Delegation of a separate and largely immutable space to each function unnecessarily grows the size of the building. It results in spending more money and consuming more materials for construction as well as more incurring higher costs for maintenance, operation and energy after construction. Another threat of static spaces is that, given they are physically arranged according to very specific parameters, they resist adapting to other uses that may happen in the space over time. In other words, fixed spaces are often single function and usually prove too rigid. Spatial flexibility considers the capacity of change in the spatial structures of buildings both in the long-term and the short-term. Spatial flexibility is responsive to momentary changes in users' needs and wants; therefore it accommodates change in the short-term. Spatial flexibility allows unfolding of different functions within a singular space; therefore, it considers long-term change in spatial needs. In this system, the plan should be divided into spaces that change and spaces that do not. The alterable spaces are divided with the use of sliding, folding, retracting, collapsing and moveable walls that can be reconfigured and rearranged according to user's wishes. This idea overlaps with Japanese traditional housing where the large rectangular plan may be easily \& readily subdivided into smaller space with different mutations possibly (with minimal effort and limited disruption). Consideration needs to be given to geometries beyond the rectilinear and to constructions beyond the orthogonal. Contemporary building technologies offer extraordinary potential.

\section{Volume}

Spatial flexibility is, traditionally, achieved in 'plan' while often the third dimension is downplayed or dismissed; however, it is essential to consider 'volume' in our approach. In other words, spatial flexibility can happen (xyz coordinates) between the levels in addition to within one level. This consideration allows for greater flexibility and considers the potentials of spatial possibilities also in the forth dimension (i.e., across time).

\section{Flow}

It is crucial to consider the flow between the spaces when users alter and adjust the spatial layouts. It is important to consider flow of space in all iterations, to delineate which space is being shared, and to pay attention to the circulation between those spaces. 
Order

In a flexible plan, there should be little or no definite hierarchical order between the spaces. In spatial flexibility the focus is on the three dimensional (horizontal \& vertical) organization and sequencing the spaces in a way that allows for differing compositional arrangements. The spatial order changes as the users alter the plan and volumetric configurations to match their needs.

\section{FUNCTIONAL FLEXIBILITY}

Functional flexibility refers to the capacity of the infill to allow different functions to unfold and be accommodated. The very first attempts to account for future changes in program with minimum demolishing can be traced back to Gerrit Rietveld's practice, in the 1920s. His goal was to prefabricate a block in which all the services such as plumbing, sinks, toilets and chimneys were concentrated (see Eldonk \& Fassbinder, 1990) with the rest of the plan then able to be freely composed and modified. In the post-war boom the demand for social housing dramatically increased with the 'open building' movement meeting the need for spaces with functional flexibility. This was coincident with the escalating land values and scarcity of land in cities, which meant smaller and more efficient dwelling units contained in multi-residential buildings. In the Netherlands, architects concentrated on the social housing sector, which had enormous effect on the architectural development of thoughts and theories related to 'open building' and 'flexible architecture'. In many buildings of the mid-20th century, the plan was divided into equally large rooms that were multifunctional. They were bedrooms at night, living rooms in the evening and on weekends, and study areas during the day for children and teenagers of the family. Mies van der Rohe specifically studied the day and night cycles in dwellings. He was interested in the fact that diurnal rhythms affect the function of the spaces. Many architects addressed this concept by integrating built-in and transformable furniture in the buildings so that the rooms could be easily reconfigured for different purposes at different times. The functional aspect of the Support and Infill was so crucial that the form was sacrificed and standardization was inevitable. In Japan, this idea was experimented in Kodan Experimental Project (KEP). In the KEP project, the building was divided into five subsystems of: "structure, skin, interior finishes, service or sanitary systems, and air conditioning equipment" (Kendall, 1999). For each subsystem, very specific performance was defined and manufacturers were assigned to develop suitable components therein. The $300 \mathrm{~mm}$ grid - a standard for modular coordination of building interior systems - is the product of this significant undertaking to increase interchangeability in the interface. The present paper views functional flexibility as basic to agile + progressive Architecture.

\section{Guideline}

In the design of buildings, functional flexibility allows different activities/uses to unfold and be accommodated within the same structure with minimum amount of difficulty, disruption and demolition.

\section{Elaboration}

Functional flexibility is one remedy to confined space contained in especially small structures. In such buildings, the functions may become limited because of the spatial limitations and confinement. Functionally fixed spaces can limit the change in the program of the building over the long run. As the spaces in conventional buildings are subdivided into smaller enclosures to accommodate current functions, demolition proves inevitable to accommodate a next-generation and expectedly different program within the same structure. In our functional flexibility approach, plans|volumes should be designed in ways that are adaptable and mutable to different needs. This can be achieved by means of specific furniture|fixtures|fittings such as stackable units and reconfigurable assemblies -- space can be easily rearranged to accommodate different functions. In this methodology, the rooms can easily adapt to any future changes in program with minimum or no demolishing, as they programmatically remain neutral.

\section{Program}

Functional flexibility accommodates a wide range of programs in a singular space. This accommodation is achieved through larger divisions incorporating stackable furniture, mutable fittings, and reconfigurable fixtures. Assemblies and systems, at a human scale and ergonomically sensitive, prove central to the equation.

\section{Productivity}

Buildings with functionally flexible plans are productive as they address day and night cycles, ever-changing number of occupants, different age groups' spatial requirements and different programs' need forlof space. They promote constant \& optimal usage of space, which is specifically efficient in terms of a plethora of operational considerations, such as for example energy use.

\section{Value}

Functional flexibility appreciates the users of space. It respects the dynamic nature of occupants and the fact that their spatial requirements change over time - in case of residential sector, the spatial requirements change even from day to night. Rooms designed with this mindset are bedrooms at night, living rooms in the evening and study rooms during the day. Functional flexibility also preferences value above cost; considering life cycle impacts and extending the financial efficiency and project viability beyond more conventional approaches.

\section{AESTHETIC FLEXIBILITY}

Aesthetic flexibility refers to the capacity of altering the form, façade arrangement and identity of the building. Concerns of rigidity in form and character, as well as lack of identity, were first raised as a protest against standardization and mass production in the 1960s. Hertzberger (1962) disagreed with the repetitive nature of such Architecture, suggesting that without changing such environments could not serve different 
functions. In his mind, the static nature of the 'support' is in paradox with the dynamic nature of dwelling. Functionally flexible design by its own cannot solve this paradox. A mindset is warranted that seeks a more intricate relation between form and function and abandons the "collective interpretation of individual life pattern" (Hertzberger, 1962). This idea reintroduces the user as an actor for whom the building should facilitate the performance. The actor should be able to determine the character of the surroundings from exterior to interior inclusive. Concepts advocated by a new generation of architects in the 1960 s seem perhaps closer to contemporary and emerging approaches to 'open building', whereby widespread adaptation and 'on-demand' customization assume a paramount position. In the emerging approaches, there are barely any fixed and static elements in the building other than the primary structure -- the new approach is more about being able to tailor the building to suit the current uses and users as well as any future changes in either or both of the two. Aesthetic flexibility also changes the clients' roles in design processes; it requires more public participation during design phases. Future tenants, in this approach, can participate in designing the infill as well as influencing the disposition and appearance of forms \& façades. This participatory approach encourages the greater regulatory milieu to reduce its role as much as possible and to let regional authorities and local companies perform to a greater extent in bona fide decisionmaking. Today, there are globally a growing number of projects that are far more flexible in character \& expression -- public participation is playing a key role in the planning and design of such projects. Advancements in technology have opened up new opportunities around this concept. The idea of 'cybernetics' and 'mechatronics' allows for highly responsive and interactive skins and infills. By the means of sensors, the responsive architecture can today more readily react to users' desires and wishes as well as responding to variable environmental conditions. The present paper views aesthetic flexibility as basic to agile + progressive Architecture.

\section{Guideline}

In the design of urban structures, applying aesthetic flexibility provides the building with a sense of character and quality of expression that can change, that can communicate with neighbours, and that can more meaningfully animate the greater context.

\section{Elaboration}

The 'flexible architecture' approaches of the mid-20th century, most notably developed in Europe and Asia, were successful in resolving numerous issues of housing demand that especially emerged post World War II. Flexible infill within fixed structures could reform and shift to create different spatial configurations according to users' needs and wants. The 'open concept' also allowed different programs and functions to unfold within the same structure with minimum demolition and costs. However, the 'open building' guidelines soon produced repetitive plans within monotonous structures as primary attention was paid to developing reconfigurable infills. Monotonous buildings and aggregate communities with a lack of identity are not merely by-products of 'open building' practice; in North America, for example, suburban houses arising via cookie cutter practices are undeniably boring, banal and "unidentifiable". What is common is perhaps oversimplification/repetition resulting from the need to manage complexity by limiting 'formulas' and by routinizing 'solutions'. Aesthetic flexibility envisions/espouses the capacity of change in form and façade; it brings about unique identity that can reflect the users' personalities, communicate with surroundings and activate the context. Advancements in digital technology and next generation cybernetics have now enabled extremely dynamic façades that are often married with clean energy generation techniques and sculptural shifts in form, which further rationalizes this approach. High performance skins that harness solar energy, provide shading and at the same time allow for appropriate day lighting are becoming more available/accessible. Digital façades that act as urban-scale messaging vehicles or 'buildingas-billboard' attractions are a trend. Façades populated with minuscule wind turbines and equipped with LEDs and small photovoltaics contribute energy while creating a more performative milieu within the city.

Innovation

'Aesthetic flexibility' deploys recent innovations in science and technology to characterize the building and provide icons for cities. We now see façades in which the automated shading apertures constantly change; not only to provide comfort for the users but also to create interesting dynamic \& poetic patterns. Small wind collectors populate whole façades to generate energy while their aggregation and moving wings animate building skins. LEDs, charged via small photovoltaic cells, constantly change a building's color while proving civic destinations and popular attractions.

Interest

Creating buildings with adaptable character and expressive flexibility is of interest to many stakeholders. Not only are building users more satisfied, as they are given tremendous control to realize their preferences, but also the broader community and greater urban realm beyond benefit from the rich aesthetics and imaginative dynamism of such buildings. There are, of course, many questions raised around architectural controls, decision management, and the balance between authority/control and democracy/choice.

\section{Balance}

'Aesthetic flexibility' provides a balance between standardization of dwelling patterns and individual interpretation of living and working. Such 'aesthetic flexibility' is about 'customization' and 'design-ondemand' which is not necessarily more expensive than the status quo - such inventive systems provide remarkable accessibility and further empowerment to users. Mechanisms for customization \& characterization introduce tremendous design opportunities and ensure more flexibility over time (both short and longer term). 


\section{RESPONSIVE | RESONANT | RESILIENT}

A concern for greater flexibility in buildings arose in the 1950s as a reaction against the excesses of 'form- follows-function', which argued that all parts of a building should be determined by, and destined for, specific uses. In practice, however, even if these uses could be determined, no allowance was made for new developments over time, yet alone the changes of use that happen in many buildings.

Richard Weston

At the core of the proposed $\mathrm{OB}$ framework are key aspects pertaining to a building's (and an architect's) obligations and opportunities. The authors cast these aspects as responsiveness, resonance and resilience.

Responsive

The skin, structure and infill should be equipped with enough elasticity to be able to respond to environmental conditions, adjust to users' needs|desires, and generate energy from renewable sources to which the building may be exposed. This means that the building is not neutral and standalone relative to its users and context. Rather, it is alive and ecologically synergistic with its surroundings.

\section{Resonant}

'Open' buildings should be designed with a meaningful balance between interior + exterior and between spatial, functional \& aesthetic aspects. Focusing on the reconfigurable 'infill' should not overshadow the potentials of dynamism, customization and energy generation in the design of an exterior shell. Ideally resonance needs to be meaningfully \& operationally active over multiple scales and successfully realized system-wide.

\section{Resilient}

The building systems should be designed with the capacity to cope with future changes with minimum demolition, cost and waste and with maximum robustness, mutability and efficiency.

The 'futuristic' architecture envisioned via the present framework proves a hybrid of spatial, functional and aesthetic flexibility -- being able to effectively \& efficiently respond to the needs to intuitively reconfigure the space, adapt to future changes in program and reflect the users' desires in real time. Each of the following three categories of spatial, functional and aesthetic flexibility contribute to the richness of an expanded + reconsidered 'open building' concept; however, each on its own will not be able to resolve the paradox of permanence (stability) - in respect to long term community interests - and change (mobility) - in respect to individual preferences. Spatial flexibility enables rooms to grow and shrink or to be subdivided differently to respond to the users' need for space. Functional flexibility allows different functions to unfold within the 'support' but it fails to fully respond to temporal needs to spatially change the layout. Aesthetic flexibility is more about the interplay \& interface between interior + exterior -- it is only rational if it reflects the greater

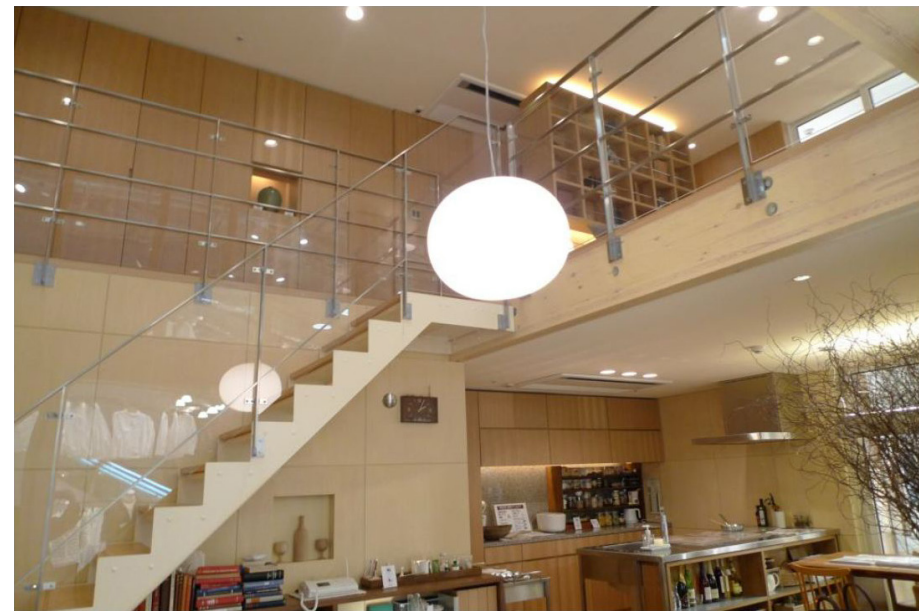

Image 5: Muji Customizable House Japan

adaptability, responsiveness and synergy between inside (infill/fit-out) and outside (skeleton/shell).

Our future architecture, considering all the current environmental, social and economic issues at play, calls for designing structures that are fully adaptable from inside out and across manifold scales. Resilience ideally overarches all dimensions. In order to do so, the best designs can be defined as those that spatially, functionally and aesthetically accommodate change. In this kind of architectural practice, collaboration among all the stakeholders is essential. Design, construction and building systems, in this methodology, are not distinct entities that develop independently. Rather, they are all inspired by the latest developments in art, science, technology, theory and practice that should be thought of and integrated from beginning to end and throughout the process.

\section{Applications | Implications}

Flexible buildings are intended to respond to changing situations in their use, operation or location. That is architecture that adapts, rather than stagnates; transforms, rather than restricts; is motive, rather than static; interacts with its users, rather than inhibits. Kronenburg (2007)

The Next 21 project in Osaka Japan is an excellent example of an Architecture where the principle of 'Open Building' has been applied to create a place that adapts well to individuals' needs and life styles. With respect to the conceptual framework delineated in the present paper, the Next 21 venture travels considerable distance in considering spatial, functional and aesthetic flexibility. However, as Open Building continues to develop the authors suggest an even stronger push towards holism and integration of design, planning, site, structure, infill, inside, outside, systems, users/uses, flexibility and adaptability. In the interior of buildings stable and accommodating infrastructure should allow for a diverse infill capable of greater mallability \& elasticity. Such diversity affords the ability for the occupants to adapt to various lifestyles and 
therefore creates spaces that can be functionally flexible. Buildings should take into account different 'needs' and 'time' aspects both in terms of inhabitation \& occupation and also re|assembly \& re|construction. Building elements need to be clearly divided into two categories: 1. longlife elements that comprise main structures such as columns, beams and floor, and, 2. short-life elements, such as nimble walls, that shape the interior/exterior (non-loadbearing) aspects of spaces with the idea that they can be easily adjusted without disturbing the overall integrity/fitness of system. Structural components, however, need to be strategically positioned and designed in a manner that affords an optimal number

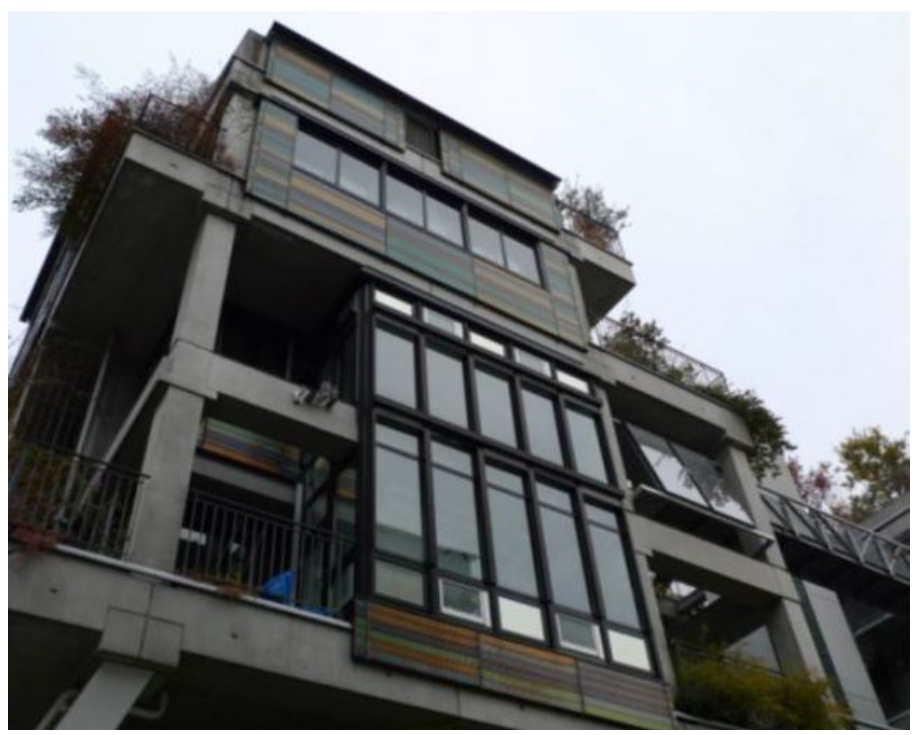

Image 6: Next 21 Demonstration Project

of reasonably achievable interior/exterior permutations. Walls (internal \& external) need to be modularized/systematized/operationalized in ways that permit deployment/redeployment within predetermined grids to meet individuals' desires and needs. While mutability of internal spaces is vital, also creating exterior walls as independent systems that can be simply reconfigured, revised and/or replaced provides users the ability to freely transform the appearance of the façade and to modify numerous qualities of space (e.g., size, views, indoor versus outdoor, look \& feel, etc.). Such
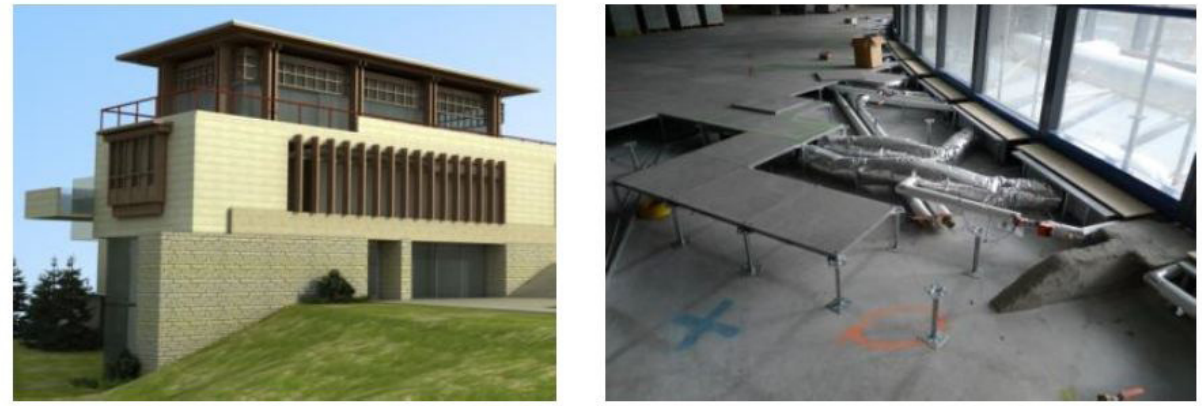

Images 7,8,9. sinclairstudio cultural project, photos of modern \& traditional flexibility. comprehensive participation across an expanded range of a building's workings (wholly within $\mathrm{x}, \mathrm{y}, \mathrm{z}$ coordinates \& over time) leads to greater choice over spatial, functional and aesthetic dimensions and arguably finds greater resonance with occupants' needs, desires, expectations and aspirations. The present model does not deny the long history and rich development of the Open Building Movement. To the contrary the framework acknowledges, respects and builds upon a remarkable foundation of both research and practice.

In an effort to further define, delineate and test the present array of ideas, the authors have been exploring the physical, cultural, social and psychological implications of their framework in an array of forward-thinking, creative and catalytic projects. Through the vehicle of sinclairstudio, and the consideration of a spectrum of building types, the authors have been testing the frameworks capacity to foster changes in mindsets, methods and materials. From cultural buildings and spiritual centers to educational facilities and super-tall buildings, the authors have considered and examined how greater adaptability and agility can be realized. Within the realm of tall buildings various explorations have considered how the envelope|skin can transcend convention to serve in energy generation (e.g., micro-wind, hydro power, solar panels, nano-technology, etc.), in perceptual stimulation (e.g., skin as computer system), and in broad communication (e.g., building as digital billboard). In considering such potential, the authors have designed a prototype for a socially interactive skin that responds to the users' occupation by expanding or retracting -- as the result creating occupiable volumes for informal social interaction. This modulated system proves potentially flexible enough to be attached to existing structures, thereby adding space to otherwise existing rigid conditions. In this conceptual design and prototyping work not only are spatial and functional flexibilities considered but also and importantly aesthetic flexibility. This latter flexibility is achieved as the skin is highly dynamic and deliberate -constantly morphing to accommodate shifting circumstances, conditions, needs and desires.

Over a plethora of different scales the authors have explored other conceptual ideas that seek a balance between spatial, functional and aesthetic flexibility. As a building's interior follows agility principles in terms 
of spatial and functional flexibility, on the exterior the building greater responsivity and adaptability to the immediate environment is sought via the use of kinetic energy. In the case of a super-tall tower design the tips of the 100+ story structures, in unoccupied zones, move freely with the wind to generate electricity for the building. This dynamic movement not only contributes to energy self-sufficiency but critically animates the skyline -- speaking to the capabilities of emerging technologies, to the direction + velocity of wind, but also to the power of aesthetic flexibility to redefine Architecture and the city in novel, creative and innovative ways. Given less than ideal efficiencies in the global building sector, coupled with the development of new theory and deployment of new technologies, the authors believe the timing is right for major advancements in open building and agile architecture. Our framework urges a far more aggressive advancement of concepts and constructions based upon emerging technologies, changing demographics, growing expectations, concerns around sustainability, heightened open-mindedness, and absolute attention to \& pursuit of systems, integration and holism. called for a relatively radical approach to more aggressively and more fruitfully consider, create and construct such design. It aims to transition mindsets + methods of Architects + Architecture, in the spirit of the late Kisho Kurokawa, from an age of the machine to the age of life. The logic and methods are especially respectful of the imperative to engage in more integrative, sensitive and thoughtful ways, above all attending to the needs of users as the basis and nexus of architecture and design.

The present paper critically considered the condition of contemporary building design, examined emerging trends, and postulated an innovative model \& philosophy for realizing a more responsive, responsible and fitting Architecture for the 21st Century. Advancing from the established foundation of Open Building $(\mathrm{OB})$ research and practice, and building upon a holistic and inter-connected strategy (Sinclair 2009) for environmental design (specifically drawing upon the Agility category), the new model places emphasis and effort on heightened agility, adaptability and appropriateness - all urgently needed in our current, uncertain and
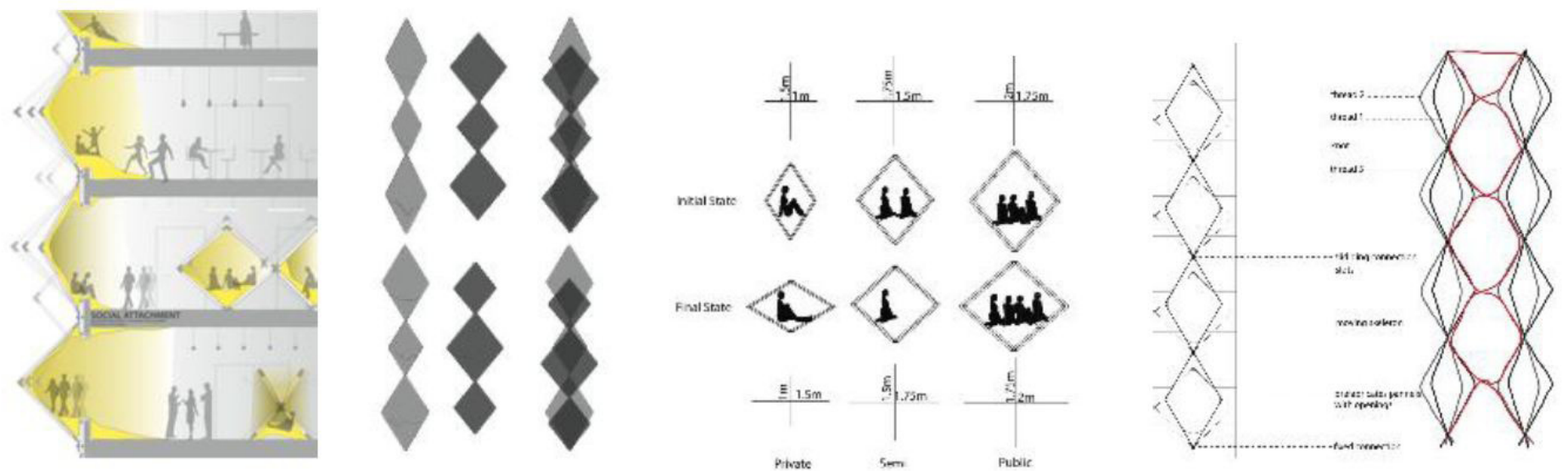

Image 10: Exploration of Occupiable, Mutable and Agile Skin

\section{SYNOPSIS + MOVING FORWARD}

People are very open-minded about new things - as long as they're exactly like the old ones.

Charles Kettering

When developing a building system it is of decisive importance whether it consists of individual part systems for the shell, the interior fit-out and the building envelope or whether it integrates all part systems.

Dorrhofer \& Rosenthal Staib

Architecture in the 21st Century, a period already understood through its dramatic movement + intense change, must be far more responsive, resonant \& resilient than designs for days long past. Rather than requiring users to shift, twist and surrender to fit into static environments, a new Architecture reacts, adjusts \& accommodates. The authors have

tumultuous times. The authors are presently pursuing greater clarity and applicability of concepts of agility in modern design, including the deployment of greater flexibility in façade design and in the construction of tall buildings. Such integrative and inventive research pursuits are sensible, warranted and remarkably promising. Given the growth of cities, advancements in technology, expectations of society and the call for greater responsibility, our explorations into Agile Architecture seem especially timely. In our proposition for reconsidered and more appropriate Architecture, people must reside centrally and the dynamic, responsive \& meaningful must eclipse the static, staid \& stale. Ingenuity, creativity, imagination + open-mindedness prove valuable and vital. 


\section{REFERENCES}

Eldonk, Jos van, and Helga Fassbinder. Flexible Fixation: The Paradox of Dutch Housing Architecture. Assen: Eindhoven University of Technology. 1990.

Habraken, N. John. The Structure of the Ordinary. Cambridge: MIT Press. 1998.

Hertzberger, Herman. "Flexibiliteit en Polyvalentie." Forum XVI 3

(1962): 115-121.

Hertzberger, Herman. Space and Learning: Lessons in Architecture.

Rotterdam: 010 Publishers. 2008.

Kendall, Stephen; Teicher, Jonathan. Residential Open Buildings.

London: Spon Press. 1999.

Kendall, Stephen. Open Building: Report on Study Trips to Japan and

the Netherlands. Technology and Economics, Silver Springs, MD. 1994.

Kronenburg, Robert. Flexible: Architecture that Responds to Change. London: Lawrence King Publishing Ltd. 2007.

Kurokawa, Kisho. The Philosophy of Symbiosis From the Age of the Machine to the Age of Life. New York: Edizioni Press. 2001

Matthews, Stanley. From Agit-Prop to Free Space: The Architecture of Cedric Price. London: Black Dog Publishing. 2007.

Price, Cedric. Re:CP. Edited by Hans Ulrich Obrist. Basel: Birkhauser. 2003.

Sinclair, Brian R. "Culture, Context and the Pursuit of Sustainability: Contemplating Problems, Parameters and Possibilities in an Increasingly Complex World." Planning for Higher Education: The Journal of the Society for College and University Planning. Volume 38, Number 1, October-December. 2009.

Sinclair, Brian R. "A Synopsis of the Invited Inaugural Lecture in the 'Sustainable Lecture Series'. Responsible Urbanism Research Lab (RURL). Zayed University | Abu Dhabi, United Arab Emirates. October 2010.

Schneider, Tatjana and Till, Jeremy. Flexible Housing. Oxford: Elsevier Inc. 2007.

Staib, Gerald, Dorrhofer, Andreas and Rosenthal, Markus. Components and Systems: Modular Construction, Design, Structure, New Technologies (Edition DETAIL). Basel: Birkhauser. 2008.

Weston, Richard. 100 Ideas that Changed Architecture. London:

Lawrence King Publishing Ltd. 2011

-

Note: All photographs @ dr. brian r. sinclair + sinclairstudio inc. 2012. 